\title{
Revisiting climate change effects on winter chill in mountain oases of northern Oman
}

\author{
Andreas Buerkert $^{1}$ (D) $\cdot$ Eduardo Fernandez $^{2} \cdot$ Beke Tietjen $^{1} \cdot$ Eike Luedeling $^{2}$
}

Received: 7 April 2020 / Accepted: 30 August 2020 /Published online: 7 October 2020

(C) The Author(s) 2020

\begin{abstract}
For centuries, traditional high-altitude oases in Oman have depended on the cultivation of deciduous fruit trees. This study explores the effects of climate change on winter chill (estimated as Chilling Hours- $\mathrm{CH}$ and Chill Portions$\mathrm{CP}$ ), a prerequisite to overcoming dormancy and initiating flowering, in three Omani oases. The results are compared with findings from an earlier study which reported a decrease in the numbers of $\mathrm{CH}$ in high-elevation oases by an average of 1.2-9.5 CH year ${ }^{-1}$ between 1983 and 2008. Location-specific weather data were obtained by merging 15 years of in situ recordings with 28 years of observations from an official weather station near the top of the investigated watershed. Between 1991 and 2018, scenarios of the past few decades show chill reductions by 75,35 and $18 \%$ when estimated in $\mathrm{CP}$ at the oases of Masayrat ar Ruwajah (1030 m a.s.l.), Qasha' (1640 m a.s.1.), and Al 'Ayn (1900 m a.s.l.), respectively. Over the course of the twenty-first century, the lowest-elevation oasis at Masayrat ar Ruwajah is projected to lose virtually all winter chill, whereas, despite significant chill losses, conditions are expected to remain viable for some of the currently grown species in the higher-elevation oases. These projected changes will compromise the cultivation of temperate fruit trees in the near future, affecting the sustainability of Omani oases. Our methods support results from earlier work performed at these locations and provide an updated procedure for assessing climate change effects on temperature-dependent systems.
\end{abstract}

Keywords Arabia · Arid environments, $\cdot$ Chill requirements $\cdot$ Fruit production · Global warming · Warm winters

Andreas Buerkert and Eduardo Fernandez contributed equally to this work.

Electronic supplementary material The online version of this article (https://doi.org/10.1007/s10584-02002862-8) contains supplementary material, which is available to authorized users.

Andreas Buerkert

buerkert@uni-kassel.de

Extended author information available on the last page of the article 


\section{Introduction}

Over the past decade, a range of studies has targeted the sustainability of oasis systems on the Arabian Peninsula, particularly in Oman (Al-Kalbani et al. 2016; Al-Rawahi et al. 2017; Cariou 2017; Hüneburg et al. 2019). This research was largely motivated by the demonstrated resilience of these millennia-old settlements, which makes them stand out as models of sustainable irrigated agriculture in an arid environment. The results of most studies have shown that the combination of carefully designed oasis infrastructure with well-textured human-made soils and socially organized irrigation (Siebert et al. 2007; Wilkinson 1977) is a key characteristic of Arabian oases. The integration of animal and crop husbandry has been highlighted as an essential mechanism for securing the substantial inputs of organic carbon and plant nutrients needed to sustain production in such a dry environment (Buerkert et al. 2005; Dickhoefer et al. 2010; Wichern et al. 2004). Elaborate water management systems that avoid salinity buildup by regular leaching of salts from the soil profiles (Luedeling et al. 2005) and a water-efficient three-storey cropping system (Al-Rawahi et al. 2014; Golombek et al. 2007) were also proposed as important features for maintaining oasis sustainability. It has become clear that it is the combination of all these factors that has allowed these systems to persist through millennia, producing the provisioning, supporting, regulating and cultural ecosystem services necessary to preserve traditional oasis societies.

Since its economic and political opening to the outside world in 1970, Oman has undergone a major socio-political transformation (Bontenbal 2016; Funsch 2015). This transformation has relegated traditional oasis agriculture, once the backbone of local livelihoods, to a part-time enterprise that heavily depends on externally hired labour. This development is threatening Oman's cultural heritage and its surprisingly large diversity of crop germplasm, which has arisen from a rich ancient trading history between Asia, the Middle East, the Mediterranean and East Africa (Al Khanjari et al. 2007a; Al Khanjari et al. 2007b; Gebauer et al. 2009; Gebauer et al. 2007; Hammer et al. 2009; Hourani and Carswell 1995; Zhang et al. 2006).

In recent years, evidence has indicated that oasis agriculture has been affected not only by rural-urban transformation leading to lifestyle changes and increasing scarcity of local agricultural labour but also by the effects of anthropogenic climate change (AlSarmi and Washington 2011). One prime area where this has been studied in detail is the oases of Wadi Muaydin in the Jabal Al Akhdar Mountains of the Western Hajar (AlSarmi and Washington 2014). This highly intersected range, which reaches $2970 \mathrm{~m}$ a.s.l. (meters above sea level) at Jabal Shams, has been used as an in situ laboratory to study the combined effects of ruralurban transformation and tourism. Some studies have also explored the effects of decreasing rainfall (Kwarteng et al. 2009) and increasing temperature on agricultural systems of the wellknown 'Hanging Gardens' in the central area of Wadi Muaydin (Al-Kalbani et al. 2015; AlKalbani et al. 2016; Luedeling and Buerkert 2008). This watershed spans an elevation gradient between 1030 and $2050 \mathrm{~m}$ a.s.1., which allows the cultivation of tropical, Mediterranean and temperate crops.

A decade ago, a study by Luedeling et al. (2009a) focused on this region to reveal the impact of climate change on winter chill, a critical climatic requirement for many Mediterranean and temperate trees to initiate budburst and flowering. The authors used sub-hourly temperatures derived from daily records of minimum and maximum temperatures from an official weather station by using a series of high-resolution data collected at three oases in Wadi Muaydin as a calibration dataset. Luedeling et al. (2009a) hypothesised that winter chill was a more sensitive indicator of climate change effects on these oases than mean or maximum 
temperatures. Using the rather simplistic, but still widely used classical Chilling Hours model $\left(\mathrm{CH}\right.$ - it quantifies the number of hours with temperatures between 0 and $7.2{ }^{\circ} \mathrm{C}$ in a given timespan) first proposed by Hutchins in 1932 (oral presentation cited by Weinberger (1950)), they detected a strong increase of winter minimum temperatures and concomitant declining winter chill between 1983 and 2008 (between -4.5 and $-9.5 \mathrm{CH}_{\text {year }}{ }^{-1}$ for the oases with temperate fruits). For simulated future scenarios, the authors predicted negative effects on flowering for temperature increases by 1 and $2{ }^{\circ} \mathrm{C}$, with clear yield implications for deciduous fruit trees, such as pomegranate (Punica granatum L.), peach (Prunus persica L. Batsch), apricot (Prunus armeniaca L.), walnut (Juglans regia L.), apple (Malus domestica (Suckow) Borkh.), pear (Pyrus communis L.) and plum (Prunus domestica L.). On Al Jabal Al Akhdar, the prevalence of these species and the sale of their fresh fruit largely determine agricultural income for local farmers and, of even higher economic importance, make the oases of Wadi Muaydin an increasingly frequented tourist attraction.

In a more recent analysis of minimum, mean and maximum daily temperature data from 1979 to 2012 for Sayh Qatanah, the town at the top of Wadi Muaydin, Al-Kalbani et al. (2015) reported a statistically significant increase in minimum $\left(+0.79{ }^{\circ} \mathrm{C}\right)$, mean $\left(+0.27{ }^{\circ} \mathrm{C}\right)$ and maximum $\left(+0.15^{\circ} \mathrm{C}\right)$ temperatures per decade. This confirms the predictions by Luedeling et al. (2009a) and underlines their expectation that minimum temperatures are a particularly sensitive indicator of climate change. To further substantiate climate change impacts, AlKalbani et al. (2015) call for more in-depth studies using temporally higher resolved data whereby the actually experienced daily temperature cycle is reconstructed.

Our study revisits the hypothesis of declining winter chill due to climate change, using a combination of high-resolution temperature measurements and stochastic simulations for past and future temperature scenarios. To this end, we collected high-resolution temperature data along the altitude gradient of Wadi Muaydin for the past 10 years. Combining the resulting records with long-term data from an official weather station and using a weather generator, we projected winter chill accumulation for two time horizons (2050 and 2085), and for two possible future climate scenarios using outputs from 15 general circulation models (GCM). We also updated the methodology of the earlier study to reflect lessons learned since its publication in 2009 .

\section{Methods}

\subsection{Study area}

Datasets were generated in three intensively cultivated terraced oases along the elevation gradient of Wadi Muaydin (Al Jabal Al Akhdar, Sultanate of Oman), a deeply incised canyon carved into the limestone-covered anticline of the country's Western Hajar Mountains. The lowest oasis in this watershed is Masayrat ar Ruwajah (57 $\left.40^{\prime} 13^{\prime \prime} \mathrm{E}, 23^{\circ} 02^{\prime} 37^{\prime \prime} \mathrm{N}\right)$ at

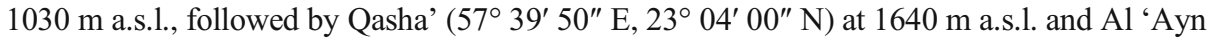
$\left(57^{\circ} 39^{\prime} 44^{\prime \prime} \mathrm{E}, 23^{\circ} 04^{\prime} 22^{\prime \prime} \mathrm{N}\right)$ at $1900 \mathrm{~m}$ a.s.l. Ecologically, the latter site is representative of a cluster of agricultural settlements that includes the neighbouring oases of Al 'Aqr and Ash Sharayjah (Fig. 1). To characterize agroclimatic conditions for deciduous fruit trees at all locations, we produced hybrid temperature records consisting of a combination of sub-hourly in situ measurements and daily-scale records of an official weather station at $<1 \mathrm{~km}$ from the top of the wadi. 


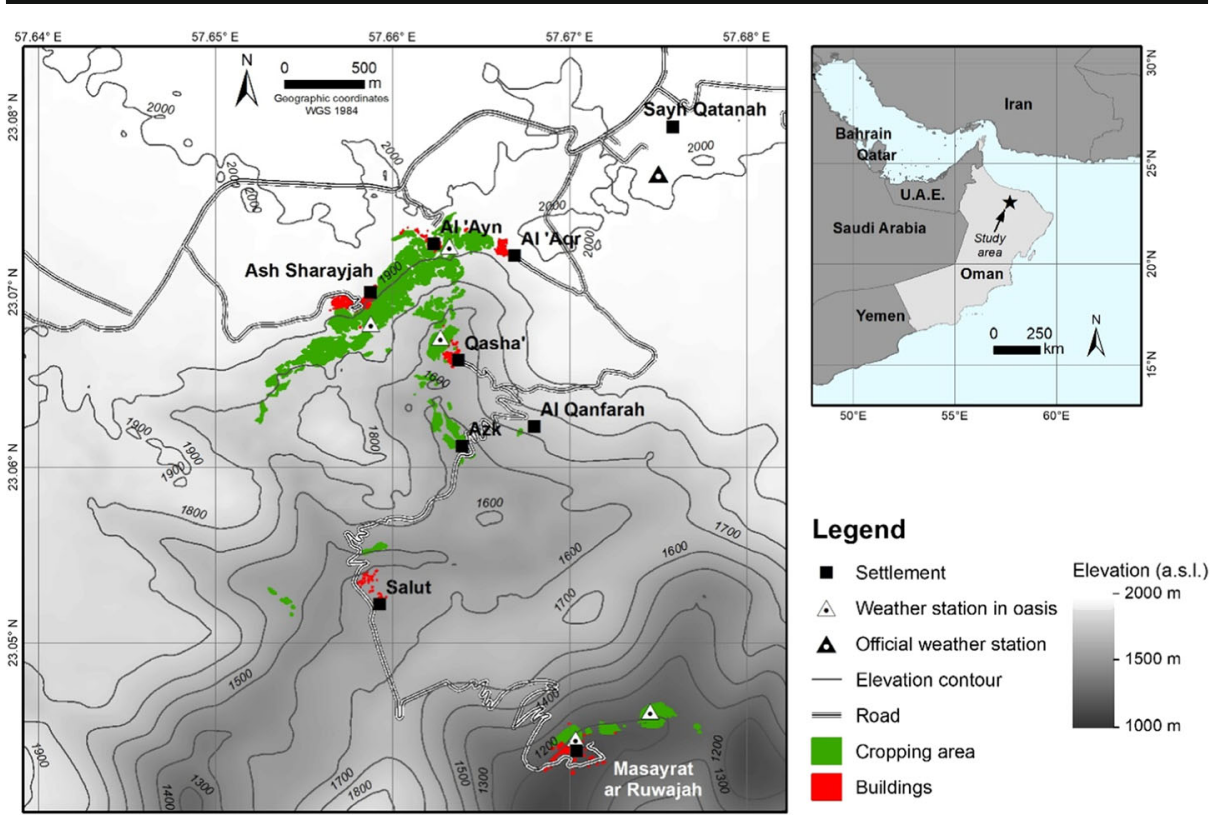

Fig. 1 Digital elevation model and map of oasis settlements of the study area on Al Jabal Al Akhdar, Western Hajar Mountains (Sultanate of Oman), comprising Wadi Muaydin and parts of the Saiq Plateau

\subsection{In situ weather data}

In order to characterize local microclimates along the elevation gradient, we placed temperature data loggers (HOBO Pro, Onset Computer Co., MA, USA) at all target sites. The loggers were installed within standard wooden weather cabinets in typical agricultural plots at $2 \mathrm{~m}$ above the ground. The loggers recorded data of air temperature and humidity at 30-min intervals from October 28, 2004, to February 15, 2019, in Masayrat ar Ruwajah, and from October 30, 2004, to February 15, 2019, in Qasha' and Al 'Ayn. Due to temporary equipment failure, largely limited to 2 years, we were only able to capture $66.4 \%, 62.3 \%$ and $64.3 \%$ of the approximately 250,500 intended measurements at Masayrat ar Ruwajah, Qasha' and Al 'Ayn, respectively. Since the primary purpose of these data was to characterize local temperature settings and calibrate transfer equations to relate recent oasis temperatures to longer-term daily data, possible gaps did not constrain further use of the data. Based on sub-hourly temperature data, we computed daily minimum and maximum temperatures for all complete days between late October of 2004 and December 31, 2018.

\subsection{Auxiliary weather data}

To fill in gaps in weather data collected in the oases, and to extend the temperature record, we used daily extreme observations from an official weather station in the vicinity as an auxiliary data source. We obtained these data from the Global Summary of the Day (GSOD) database of the National Climatic Data Center (NCDC) maintained by the United States National Oceanic and Atmospheric Administration (NOAA) using functions contained in the chillR package (Luedeling 2019; Luedeling 2020b) for R (R Core Team 2020). We downloaded minimum and maximum temperature data recorded between 1983 and 2019 by a meteorological station 
at Saiq (no. 412540; $23^{\circ} 04^{\prime \prime}$ N, $57^{\circ} 39^{\prime \prime}$ E; $1955 \mathrm{~m}$ a.s.1.), located at the top of Wadi Muaydin. Out of 13,514 intended observations, this weather station presented $14.0 \%$ and $13.9 \%$ of missing minimum and maximum temperature records, respectively (Fig. 2).

\subsection{Filling missing values}

Given the availability of official records from January 1, 1983, to December 31, 2018, we computed daily minimum and maximum temperatures for each day of the records at each oasis and extended the datasets backwards until 1983 by adding records termed 'missing data' for all times when no observations were available from the oasis stations (oasis datasets shown in Fig. 2). This procedure yielded four datasets (for all three oases and for the Saiq station) containing incomplete records of daily temperature data for the entire study period.

We then filled gaps in the daily minimum $\left(T_{\min }\right)$ and maximum $\left(T_{\max }\right)$ temperature records of the three oases using bias-corrected temperature data from the Saiq station. For each oasis, we first computed the difference in $T_{\min }$ and $T_{\max }$ between the oasis and the official weather station for all days that both locations had data for. We then computed the mean bias in $T_{\min }$ and $T_{\max }$ between the locations as the mean of this dataset of daily temperature differences. As a further measure of the similarity of the temperature records, we calculated the standard deviation of the daily temperature differences, also separately for $T_{\min }$ and $T_{\max }$. A low value for this metric indicates that the temperature records are similar except for a mean bias. This implies that the record from the official station, after adjustment for between-station bias, can be used to fill gaps in the oasis dataset. A high standard deviation of daily between-station biases would indicate more fundamental differences in local temperature dynamics that may compromise the suitability of the official record as an auxiliary data source.
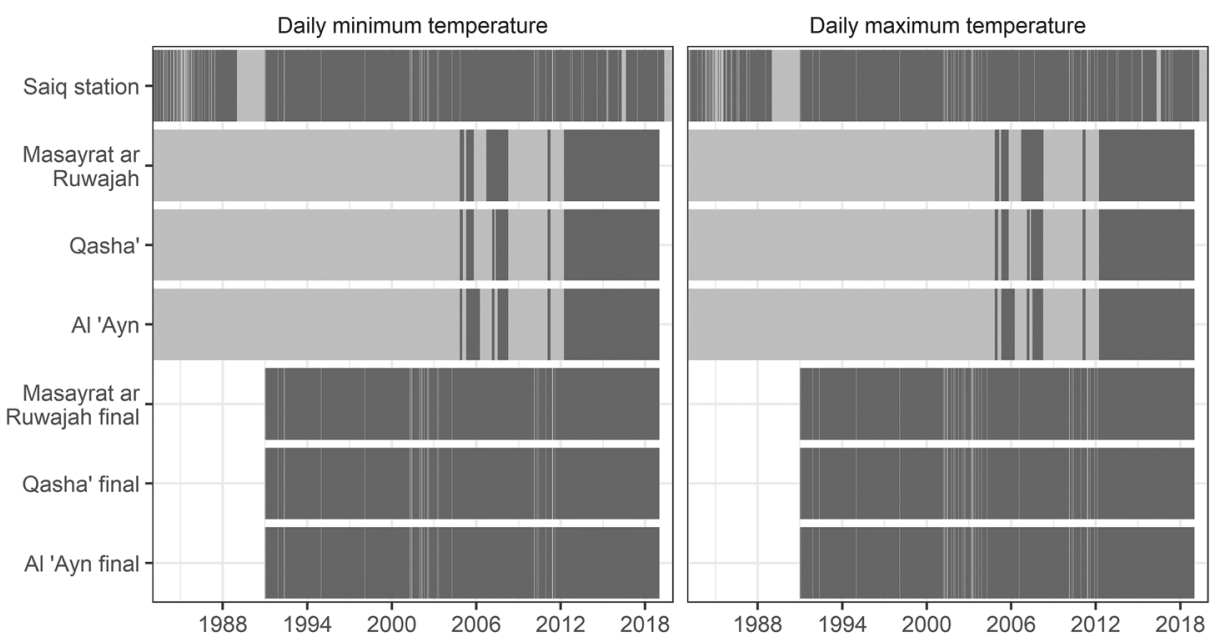

Missing

Available

Fig. 2 Graphical representation of the datasets used in this analysis. Daily minimum and daily maximum temperature panels show availability (dark grey bars) of records between 1983 and 2019 for the three oases (Masayrat ar Ruwajah, Qasha' and Al 'Ayn) and for the official weather station at Saiq. The bottom three datasets represent the final records for the three oases after the patching procedure. Note that remaining gaps in these datasets were filled through linear interpolation 
For all oases in the Wadi Muaydin watershed, the standard deviation of the daily temperature bias relative to the official weather station at Saiq was low, ranging between $1.0{ }^{\circ} \mathrm{C}$ for $T_{\max }$ at $\mathrm{Al}$ 'Ayn and $2.0^{\circ} \mathrm{C}$ for $T_{\min }$ at Qasha' (Table 1). These findings indicate that the shapes of temperature curves at all locations were sufficiently similar to allow using records from Saiq to fill gaps in temperature records collected in the oases.

For each oasis, we adjusted the records of $T_{\min }$ and $T_{\max }$ from Saiq for the between-station temperature bias, which ranged from $0.2{ }^{\circ} \mathrm{C}$ for $T_{\min }$ at $\mathrm{Al}$ 'Ayn to $7.1^{\circ} \mathrm{C}$ for $T_{\max }$ at Masayrat ar Ruwajah (Table 1), and used the resulting records to fill gaps in the oasis temperature datasets.

This procedure resulted in three datasets containing values for about $89 \%$ of daily extreme temperatures between 1983 and 2018. Since most of the remaining gaps (1188 out of 1426) were found between 1983 and 1990 (Fig. 2), we excluded these years from the analysis. For the period 1991-2018, we applied linear interpolation (Luedeling 2018) to fill minimum temperature records for 233 days in Masayrat ar Ruwajah and Qasha' (2.27\%), and 238 in Al 'Ayn (2.32\%). A similar number of gaps were interpolated for daily maximum temperature records at each oasis (229 at Masayrat ar Ruwajah and Qasha', and 234 at Al 'Ayn). This procedure yielded a dataset with complete daily extreme temperature records for a period of 28 years.

\subsection{Past and projected future weather scenarios}

We evaluated climatic conditions based on temperature records from each oasis (with records supplemented with data from the auxiliary station, as described above). While chill accumulation and temporal dynamics can be derived directly from such a dataset, the inter-annual variation that characterizes temperature data can obscure long-term trends. This variation also makes it difficult to appraise climatic risks, because each annual temperature record is essentially a random draw from an unknown distribution of plausible temperature outcomes for a given year. Knowledge of this unknown distribution, which shifts gradually as the climate changes, would be much more useful for climate risk assessment than knowing the temperatures that actually occurred. To facilitate such risk appraisal, which can be critical for growers deciding on what fruit trees to plant, we worked with temperature scenarios that aimed to capture the typical temperature conditions at particular points in time.

Table 1 Control parameters for the filling procedure applied to the missing values from the oasis temperature records. Means and distribution parameters (5th, 50th and 95th quantile) of the temperature distributions for $T_{\min }$ and $T_{\max }$ are based on all days for which both the temperature record from Saiq and the dataset from the respective oasis had data. The standard deviation of the temperature bias serves as a measure of the similarity of the temperature patterns between locations, while the mean bias denotes the temperature differential that needs to be adjusted for when using the auxiliary dataset to fill gaps

\begin{tabular}{|c|c|c|c|c|}
\hline \multirow[t]{2}{*}{ Oasis } & \multirow[t]{2}{*}{ Metric } & \multicolumn{2}{|c|}{ Mean (5th/50th/95th percentiles) } & \multirow{2}{*}{$\begin{array}{l}\text { Temperature bias } \\
\text { Mean } \pm \text { standard deviation }\end{array}$} \\
\hline & & Temperature at Saiq & Temperature in oasis & \\
\hline \multirow[t]{2}{*}{ Al 'Ayn } & $\mathrm{T}_{\min }\left({ }^{\circ} \mathrm{C}\right)$ & $13.8(4.4 / 13.5 / 22.8)$ & $14.0(5.4 / 13.8 / 22.5)$ & $0.2 \pm 1.2$ \\
\hline & $\mathrm{T}_{\max }\left({ }^{\circ} \mathrm{C}\right)$ & $22.9(13.8 / 22.7 / 31.5)$ & $23.6(14.5 / 18.1 / 20.5)$ & $0.7 \pm 1.0$ \\
\hline \multirow[t]{2}{*}{ Qasha' } & $\mathrm{T}_{\min }\left({ }^{\circ} \mathrm{C}\right)$ & $14.1(4.4 / 14.2 / 22.9)$ & $16.0(6.9 / 16.4 / 24.2)$ & $1.8 \pm 1.5$ \\
\hline & $\mathrm{T}_{\max }\left({ }^{\circ} \mathrm{C}\right)$ & $23.2(13.8 / 23.3 / 31.6)$ & $28.0(23.5 / 28.7 / 30.5)$ & $4.7 \pm 2.0$ \\
\hline \multirow[t]{2}{*}{ Masayrat ar Ruwajah } & $\mathrm{T}_{\min }\left({ }^{\circ} \mathrm{C}\right)$ & $13.9(4.1 / 13.9 / 22.8)$ & $19.8(10.7 / 20.2 / 28.3)$ & $5.9 \pm 1.8$ \\
\hline & $\mathrm{T}_{\max }\left({ }^{\circ} \mathrm{C}\right)$ & $23.0(13.5 / 23.0 / 31.5)$ & $30.0(31.9 / 36.6 / 38.4)$ & $7.1 \pm 1.5$ \\
\hline
\end{tabular}


Our scenarios consisted of 101 replicates of plausible annual temperature records for given years, which we produced with the RMAWGEN weather generator (Cordano and Eccel 2019). These 101 replicate years of temperature data contained a total of 100 winter seasons, which provided a robust basis for assessing the risk of chill accumulation falling below certain thresholds. Weather generators are statistical models that simulate realistic random sequences of atmospheric variables such as temperature, precipitation and wind (Wilks and Wilby 1999) based on a calibration dataset. We first calibrated the weather generator for each of the oases using the 28year records of daily extreme temperatures generated for these locations (section 2.4 of materials and methods). It is worth noting that the RMAWGEN weather generator only produces data for minimum and maximum temperatures (Cordano and Eccel 2019). We then estimated mean monthly minimum and maximum temperatures for each year of interest via a 15-year running mean function implemented in the chillR package and used these data as input to the weather generator. Using a running mean function, instead of a linear regression function as in previous studies (Fernandez et al. 2020a), allowed us to closely track local temperature change dynamics over the past few decades. Following common practice in climate-related assessments (Benmoussa et al. 2018; del Barrio et al. 2020; Fernandez et al. 2020b), we produced temperature scenarios for eight past points in time (1991, 1995, 1999, 2003, 2007, 2011, 2015 and 2018).

We used the same procedure to produce representative records for projected future climate scenarios, except that mean monthly temperature extremes were not obtained from historic records, but from a database containing future temperatures projected by several climate models. We acquired these data from the ClimateWizard database maintained by the International Center for Tropical Agriculture (CIAT) using an application-programming interface (https://github.com/CIATDAPA/climate_wizard_ api). This database contains data for 15 general circulation models (GCM, Table 2), for two Representative Concentration Pathways (RCP4.5 and RCP8.5) and for two future time periods (2035-2065, denoted as 2050, and 2070-2100, denoted as 2085). Climate projections based on the RCP4.5 scenario generally feature moderate planetary warming, whereas RCP8.5 produces relatively strong warming. We then used these scenarios as inputs to the weather generator to produce 101 simulated years for each combination of oasis, RCP, year and GCM.

\subsection{Winter chill estimation}

The chill accumulation season in Wadi Muaydin was defined as November 1 to April 30. For the sake of comparison with the earlier assessment (Luedeling et al. 2009a), we computed chill accumulation using the classical Chilling Hours model (Hutchins, 1932, cited by Weinberger (1950)) in addition to the generally preferable Dynamic Model (Erez et al. 1990; Fishman et al. 1987a; Fishman et al. 1987b). Compared with the Chilling Hours model, the Dynamic Model for chill quantification was developed using a biological process-based approach. This model assumes that low temperatures trigger the formation of an intermediate labile compound that can be destroyed by high temperatures (Erez et al. 1990; Fishman et al. 1987a; Fishman et al. 1987b). After a certain amount of this intermediate compound has accrued, a permanent Chill Portion is formed. Chill Portions are then accumulated until the end of dormancy. 
Table 2 General circulation models (GCM) used in this study and the research centre in which they were developed

No. General circulation Research centre model

01 bcc-csm1-1

02 BNU-ESM

03 CanESM2

04 CESM1-BGC

05 MIROC-ESM

06 CNRM-CM5

07 ASSESS1-0

08 CSIRO-Mk3-6-0

09 GFDL-CM3

10 GFDL-ESM2G

11 GFDL-ESM2M

12 inmem 4

13 IPSL-CM5A-LR

14 IPSL-CM5A-MR

15 CCSM4
Beijing Climate Center Climate System Model (BCC CSM), China

College of Global Change and Earth System Science, Beijing Normal University (BNU), China

Canadian Centre for Climate Modelling and Analysis (CCCma), Canada

U.S. Department of Energy (DOE), USA

Japan Agency for Marine-Earth Science and Technology (JAMSTEC) and Centre for

Climate System Research/National Institute for Environmental Studies, Japan

Centre National de Recherches Météorologiques (CNRM), France

Australian Research Council's Centre of Excellence for Climate System Science (ACCESS), Australia

CSIRO Marine and Atmospheric Research and the Queensland Climate Change

Centre of Excellence (QCCCE), Australia

Geophysical Fluid Dynamics Laboratory (GFDL), USA

Geophysical Fluid Dynamics Laboratory (GFDL), USA

Geophysical Fluid Dynamics Laboratory (GFDL), USA

Institute of Numerical Mathematics of the Russian Academy of Sciences (INM RAS), Russia

Institut Pierre Simon Lapace (IPSL), Climate Modelling Centre, France

Institut Pierre Simon Lapace (IPSL), Climate Modelling Centre, France

Community Earth System Model (CESM), USA

\subsection{Hourly temperature generation}

Both the Chilling Hours Model and the Dynamic Model require hourly temperature data as input. Such hourly records were derived from daily minimum and maximum temperatures using typical daily temperature curves that were empirically inferred from data recorded in each oasis. Based on mean hourly temperatures (derived from measured sub-hourly temperatures) and daily temperature extremes, we estimated, separately for each month of the year, the typical relationship between temperature during each hour of the day and the daily temperature range (i.e. what fraction of daily warming or cooling had occurred by the respective hour). Specifically, we calculated for each month the mean temperature for every hour of the day. The function to compute hourly temperatures was derived from the resulting set of 24 hourly temperatures that represented the typical temperature profile of a day in the specific month. Based on this temperature profile, we determined the hours of the day when the lowest and highest values were recorded. $T_{\min }$ and $T_{\max }$ were assumed to occur at these times of day. To compute temperatures for all other hours of the day, we subtracted the lowest hourly temperature from all hourly values and divided the results by the range between the highest and lowest temperatures of the daily profile. The resulting numbers represent the fraction of daily warming that has typically occurred at any given hour of the day, for the specific month. Multiplying these factors by the temperature range $\left(T_{\max }-T_{\min }\right)$ of a given day and adding $T_{\min }$ results in a reasonable estimate of the temperature at this hour.

We adopted this site-specific empirical procedure to account for the rugged topography of Wadi Muaydin, where several oases, particularly Qasha' and Masayrat ar Ruwajah, are shaded by surrounding mountains for substantial parts of the day. This geographic setting precludes the use of idealized temperature curves that usually only account for latitude-dependent 
differences in sunset and sunrise times (Linvill 1990). Additional information on this procedure can be found in the supplementary materials accompanying this manuscript.

\subsection{Projections and analyses}

Based on the hourly temperature datasets for all oases, we computed site-specific winter chill for all years of all scenarios, and for all locations, using automated functions of the chillR package. Even though several lines of evidence have pointed to the Dynamic Model as being more reliable in warm locations compared with the fairly simple Chilling Hours model (Luedeling 2012), we included Chilling Hours in our analysis to allow comparison with earlier chill assessments for these locations reported by Luedeling et al. (2009a). All procedures for running simulations, analysing data and producing figures were implemented in the $\mathrm{R}$ programming environment (R Core Team 2020). We included a detailed reproducible example as supplementary materials accompanying this manuscript (supplementary materials). To detect trends in observed historic chill levels, we applied the Mann-Kendall test (Mann 1945; Stuart 1956), a commonly used tool for detecting trends in time series, using a critical $p$ value of 0.05 .

\section{Results}

In all three oases of Wadi Muaydin, temperature records of the past 28 years indicated declining levels of winter chill. These declines were more pronounced when using Chilling Hours $(\mathrm{CH})$ to quantify chill than when using Chill Portions (CP), the units of the Dynamic Model, and they increased with altitude when comparing absolute values. Both effects were also reflected in the future projections for both the RCP4.5 and RCP8.5 scenarios (Figs. 3, 4 and 5).

\subsection{Masayrat ar Ruwajah}

When measured in Chilling Hours, historic chill declined (Kendall's tau $=-0.47, p<0.01$ ) by an average of $1.68 \mathrm{CH}$ per year (slope determined by linear regression). This trend was less clear, when Chill Portions (according to the Dynamic Model) were used to quantify chill (Kendall's tau $=-0.27, p=0.053$ ). In Chilling Hours $(\mathrm{CH})$, winter chill declined from $20 \mathrm{CH}$ in the winter of 1991/1992 to $0 \mathrm{CH}$ in 2017/2018. Regarding simulated historic scenarios, we detected a clear declining trend in chill accumulation when using the Chilling Hours model. For the scenario of typical conditions in 1991, the median chill accumulation (among the 100 replicate winter seasons of the scenario) was $29.5 \mathrm{CH}$ (percentile $25 \%=17.25 \mathrm{CH}$, percentile $75 \%=50 \mathrm{CH})$, whereas by the 2018 scenario, the median had decreased to $5.5 \mathrm{CH}(\mathrm{P} 25 \%=1$ $\mathrm{CH}, \mathrm{P} 75 \%=13.25 \mathrm{CH}$ ), implying a decline in chill accumulation by $81 \%$. When analysing winter chill according to the Dynamic Model, the reduction between the 1991 and 2018 scenarios amounted to a decrease by $74 \%$, with median values of $4.0 \mathrm{CP}$ for 1991 and $1.0 \mathrm{CP}$ for 2018 .

According to projections for future scenarios, chill decline is expected to continue, with 0 $\mathrm{CP}$ estimated as the median of the typical distributions in Masayrat ar Ruwajah for nearly all future scenarios (Fig. 3). When using the Chilling Hours model, median chill accumulation amounted to $7 \mathrm{CH}$ (across all GCMs) in the RCP4.5 scenario by 2050. By 2085, we estimated 


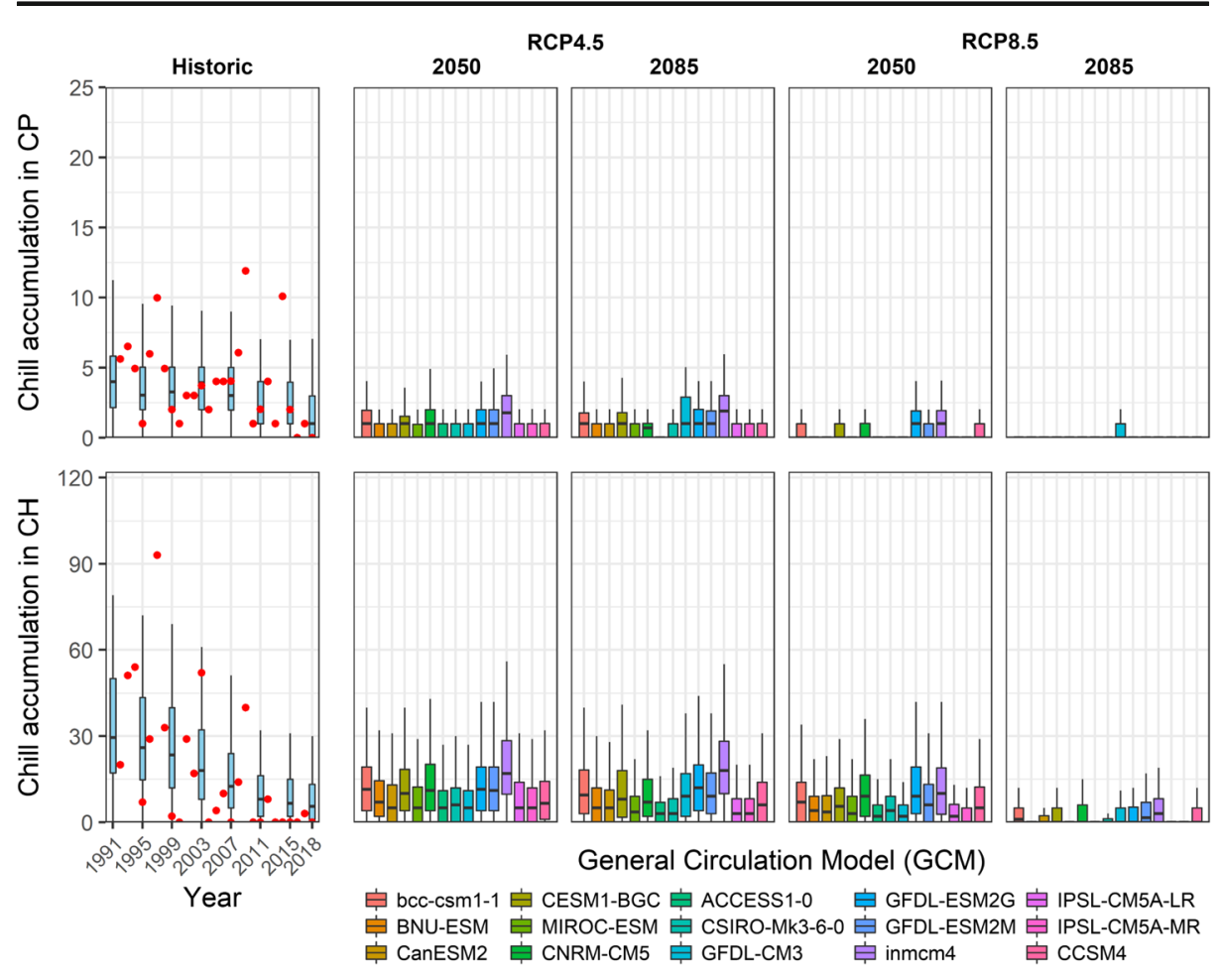

Fig. 3 Chill distribution (calculated in 'Chilling Hours- $\mathrm{CH}$ ' and 'Chill Portions-CP') during the dormant season (November 1 to April 30) for historic observed, historic simulated and future projected scenarios in Masayrat ar Ruwajah (1030 m a.s.1.). In historic panels (left), red dots indicate actual chill accumulation for each season, whereas blue boxplots show the chill distribution across 100 simulated dormant seasons in historic temperature scenarios (representing typical conditions in 1991, 1995, 1999, 2003, 2007, 2011, 2015 and 2018). In the four right-hand panels (RCP4.5 and RCP8.5), boxplots illustrate the expected chill distribution according to 15 GCMs (Table 2) by two time horizons (2050 and 2085) under two greenhouse gas concentration scenarios by the end of the twenty-first century. Each boxplot illustrates chill accumulation for 100 simulated winter seasons, with the edges of the boxes indicating the 25 th and 75 th percentiles

a decrease to $6 \mathrm{CH}$ for RCP4.5. Even lower chill totals were estimated for the RCP8.5 scenario (Fig. 3).

\subsection{Qasha'}

In Qasha', winter chill measured in Chilling Hours declined (Kendall's tau $=-0.53, p<0.01$ ) by an average of $12.75 \mathrm{CH}_{\text {year }}{ }^{-1}$ (based on linear regression), from $370 \mathrm{CH}$ in the winter of $1991 / 1992$ to $208 \mathrm{CH}$ in 2017/2018. Again, global warming effects were less clear and nonsignificant for chill accumulation quantified in CP (red dots in Fig. 4). These effects became clearer when analysing the simulated historic scenarios (blue boxplots in Fig. 4). For the 1991 scenario, we estimated a median chill accumulation of $439 \mathrm{CH}(\mathrm{P} 25 \%=377 \mathrm{CH}, \mathrm{P} 75 \%=495$ $\mathrm{CH})$ and 29.7 CP (P25\% $=26.6 \mathrm{CP}, \mathrm{P} 75 \%=32.4 \mathrm{CP})$. For the most recent simulated scenario year (2018), median seasonal chill accumulation was substantially lower at $175 \mathrm{CH}$ and 19.2 CP. This reduction represents a decline by $60 \%$ and $35 \%$, for Chilling Hours and Chill Portions, respectively. 

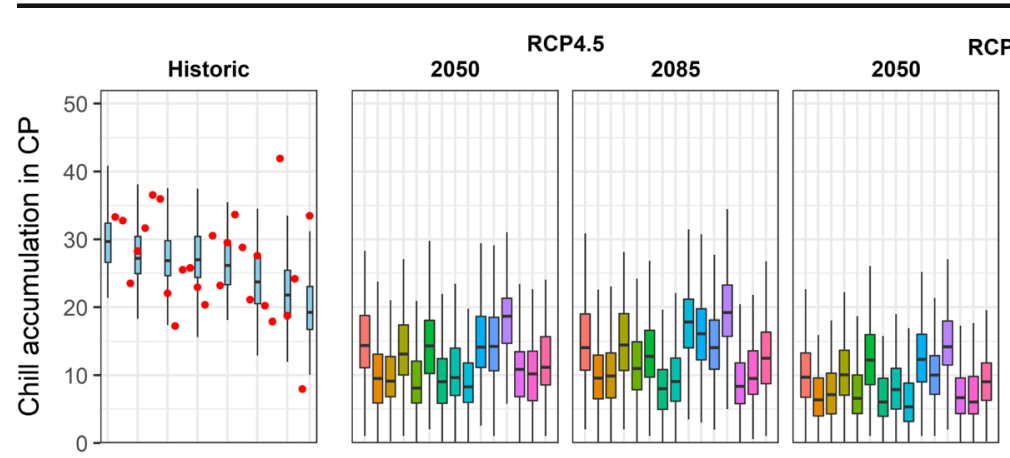

CP8.5
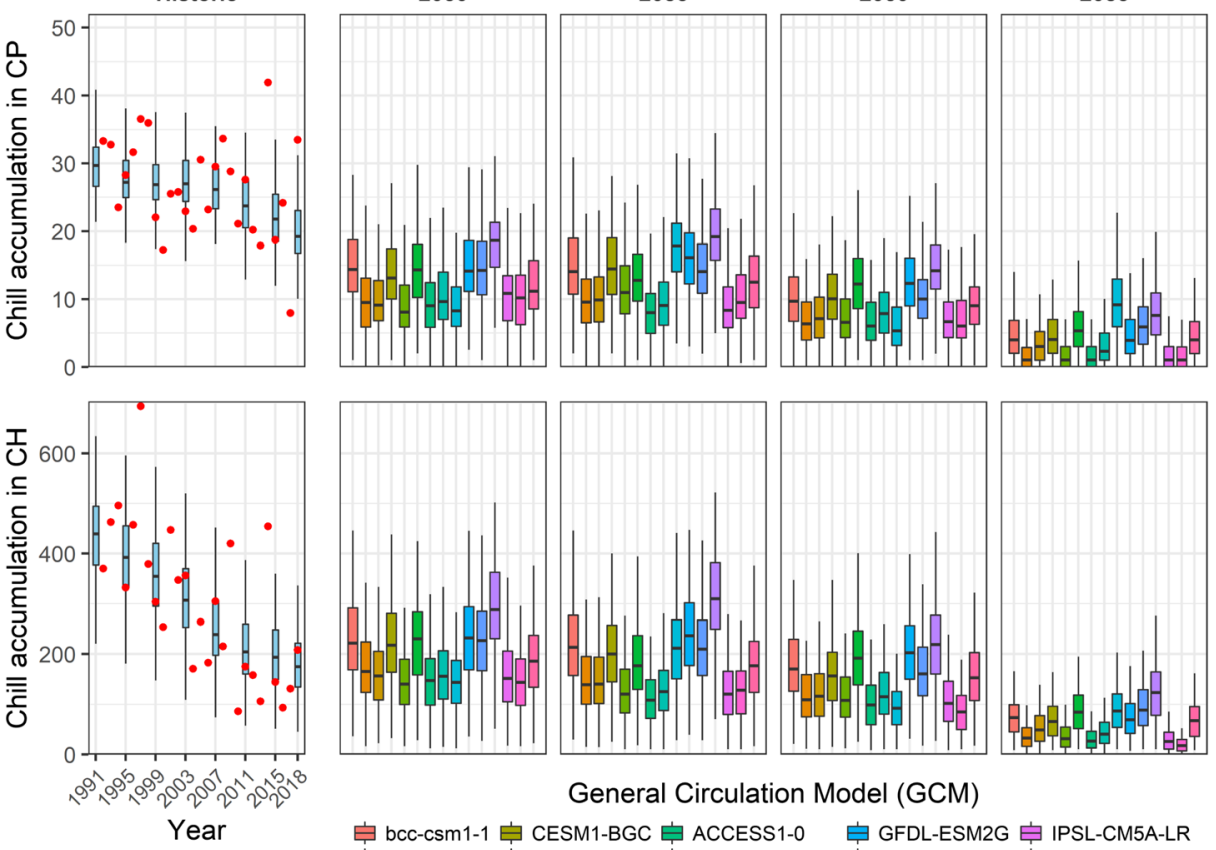

General Circulation Model (GCM)

追 bcc-csm1-1 升 CESM1-BGC ACCESS1-0 升 GFDL-ESM2G 追 IPSL-CM5A-LR 帛 BNU-ESM MIROC-ESM CSIRO-MK3-6-0 帛 GFDL-ESM2M 帛 IPSL-CM5A-MR 追 CanESM2 CNRM-CM5 GFDL-CM3 追 inmcm4 追 CCSM4

Fig. 4 Chill distribution (calculated in 'Chilling Hours- $\mathrm{CH}$ ' and 'Chill Portions-CP') during the dormant season (November 1 to April 30) for historic observed, historic simulated and future projected scenarios in Qasha' (1640 m a.s.1.). In historic panels (left), red dots indicate actual chill accumulation for each season, whereas blue boxplots show the chill distribution across 100 simulated dormant seasons in historic temperature scenarios (representing typical conditions in 1991, 1995, 1999, 2003, 2007, 2011, 2015 and 2018). In the four right-hand panels (RCP4.5 and RCP8.5), boxplots illustrate the expected chill distribution according to 15 GCMs (Table 2) by two time horizons (2050 and 2085) under two greenhouse gas concentration scenarios by the end of the twenty-first century. Each boxplot illustrates chill accumulation for 100 simulated winter seasons, with the edges of the boxes indicating the 25 th and 75 th percentiles

Using all general circulation models, the projected chill accumulation ranged between 129 and $256 \mathrm{CH}$ (P25\% and P75\%) for the scenario RCP4.5 by 2050. By 2085 and using the same RCP scenario, the range for projected chill slightly decreased to 114-241 CH. Chill in CP was projected to decrease by $36 \%$ for the RCP4.5 scenario by 2085 relative to the simulated past scenario of 2018. In the RCP8.5 scenario by 2050, this reduction increased to $55 \%$ (using the same reference year as a baseline).

\subsection{Al ‘Ayn}

In $\mathrm{Al}$ 'Ayn, which is dominated by temperate fruit crops and cultivation of roses, winter chill in Chilling Hours declined very strongly (Kendall's tau $=-0.21, p<0.01$ ), but similar as for the other oases, there was no significant trend in chill accumulation when estimated in Chill Portions. Global warming led to a decline of $17.8 \mathrm{CH}_{\text {year }}{ }^{-1}$ (based on linear regression) from $658 \mathrm{CH}$ in the season of $1991 / 1992$ to $421 \mathrm{CH}$ in the $2017 / 2018$ season (Fig. 5). Analysing the simulated historic scenarios, we found a clear decline in the numbers of both CH and CP from 1991 to 2018. The 


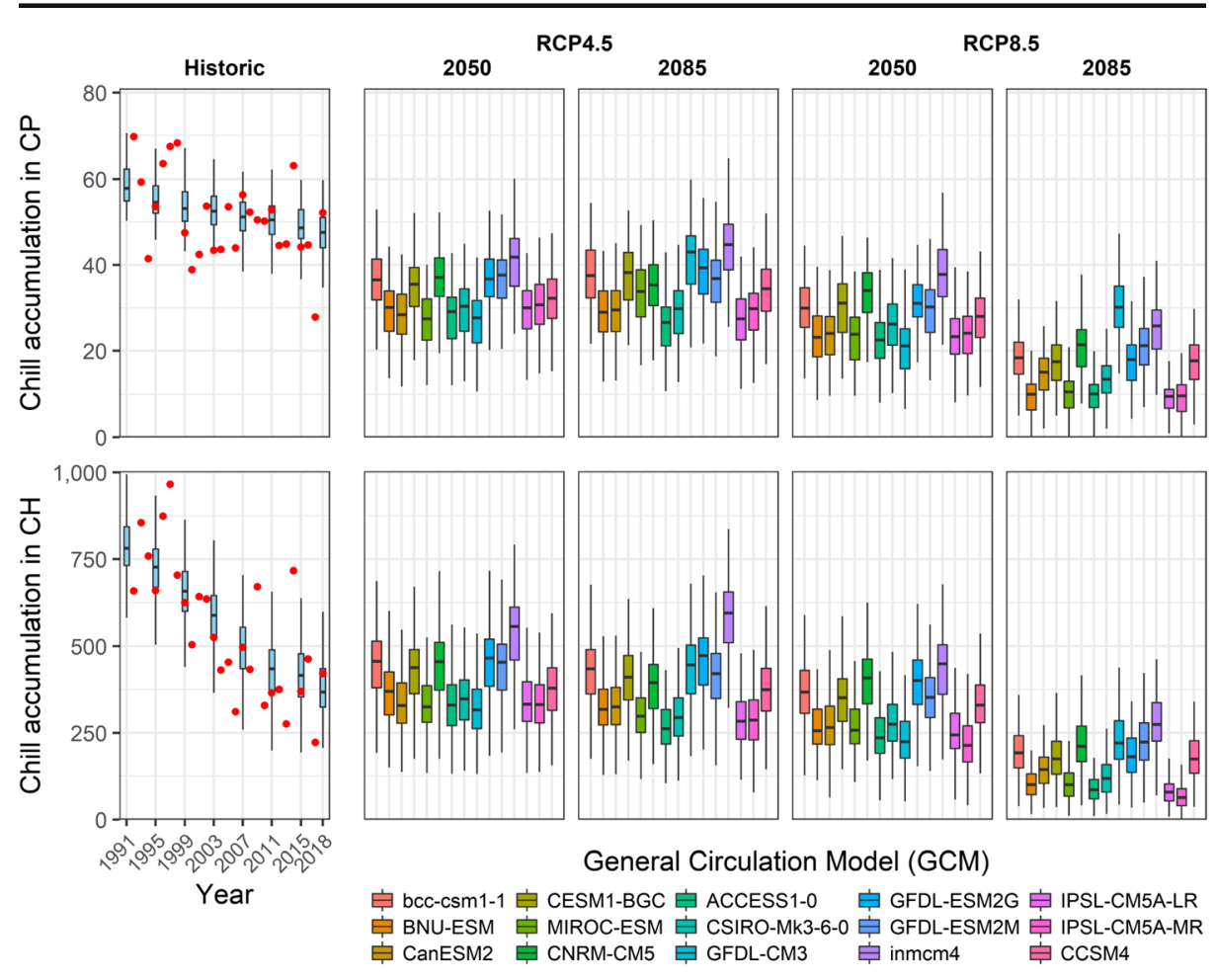

Fig. 5 Chill distribution (calculated in 'Chilling Hours- $\mathrm{CH}$ ' and 'Chill Portions - CP') during the dormant season (November 1 to April 30) for historic observed, historic simulated and future projected scenarios in $\mathrm{Al}$ 'Ayn (1640 m a.s.1.). In historic panels (left), red dots indicate actual chill accumulation for each season, whereas blue boxplots show the chill distribution across 100 simulated dormant seasons in historic temperature scenarios (representing typical conditions in 1991, 1995, 1999, 2003, 2007, 2011, 2015 and 2018). In the four right-hand panels (RCP4.5 and RCP8.5), boxplots illustrate the expected chill distribution according to 15 GCMs (Table 2) by two time horizons (2050 and 2085) under two greenhouse gas concentration scenarios by the end of the twenty-first century. Each boxplot illustrates chill accumulation for 100 simulated winter seasons, with the edges of the boxes indicating the 25 th and 75 th percentiles

median chill accumulation for the reference year 1991 was $781 \mathrm{CH}$ and $57.8 \mathrm{CP}$, whereas for the reference year of 2018 , these values decreased to $368 \mathrm{CH}$ and $47.5 \mathrm{CP}$. This represents a reduction by $53 \%$ in $\mathrm{CH}$ and $18 \%$ in $\mathrm{CP}$.

Regarding future scenarios, our results showed similar projections in both $\mathrm{CP}$ and $\mathrm{CH}$ for the RCP4.5 scenario by 2050 and 2085. The median chill accumulation for the RCP4.5 scenario by 2050 was $32.3 \mathrm{CP}(\mathrm{P} 25 \%=26.9 \mathrm{CP}, \mathrm{P} 75 \%=37.4 \mathrm{CP})$ and $380 \mathrm{CH}(\mathrm{P} 25 \%=305 \mathrm{CH}, \mathrm{P} 75 \%=469 \mathrm{CH})$. By 2085 in the same RCP scenario, these values were $33.5 \mathrm{CP}$ and $361 \mathrm{CH}$. In the RCP 8.5 scenario by the end of the twenty-first century, winter chill was projected to decrease by $68 \%$ (using the Dynamic Model) and 40\% (using the Chilling Hours model) relative to the simulated scenario for 2018.

\section{Discussion}

Our projections showed a decline in chill accumulation for all oases of Wadi Muaydin for both historic and future scenarios. While past trends were not statistically significant for all time 
series of actual chill observations, trends were clear in the typical chill distribution scenarios for eight past reference years. This finding highlights the benefits of using past temperature scenarios rather than basing trend analysis on metrics derived from observed temperatures only. Stochastic weather scenarios are less susceptible to inter-annual variation, and they provide an illustration of the gradual shift in the chances of climatic risk events that is brought about by climatic change. A number of studies have identified comparable trends in chill availability for California (Luedeling et al. 2009b), Chile (Fernandez et al. 2020a), Germany (Chmielewski et al. 2012), Australia (Darbyshire et al. 2016) and Tunisia (Benmoussa et al. 2018). In our previous study (Luedeling et al. 2009a), we identified a chill decline by $9.5 \mathrm{CH}$ per year at Al 'Ayn (from the season 1983/84 to 2007/08). Using the records for the period 1991-2018, this decline reached $17.8 \mathrm{CH}_{\text {year }}{ }^{-1}$. This may be explained by increasingly warm temperatures observed in recent years (after 2008).

When comparing specific winter seasons between the two studies, our earlier calculations appear to have underestimated the decline. For instance, for the 1996/1997 season, the difference between studies was about $400 \mathrm{CH}$ at $\mathrm{Al}$ 'Ayn. This may be explained by the procedure we used to derive hourly temperature records. In the earlier study (Luedeling et al. 2009a), we used partial least squares regression to relate hourly temperatures in each oasis directly to daily extreme temperatures of the long-term records from Saiq. While we included simulated daylength in these equations, we did not consider any other mechanism to adjust for seasonal effects. It seems likely that this procedure did not fully account for the intra-annual variation in daily temperature dynamics in these oases, where seasonal changes are amplified by the local topography. This topography substantially influences both daytime warming and nighttime cooling, leading to relatively cooler days in winter than in summer, compared with temperatures at Saiq, which is located on the adjacent mountain plateau and thus not subject to the shading effect of surrounding mountains. This earlier procedure may thus have systematically overestimated temperatures during the coolest hours of the day. Given the high (probably excessive) sensitivity of the Chilling Hours model to temperature variation (Luedeling et al. 2009c), such a bias can lead to underestimates of seasonal chill levels. The empirical procedure applied in the present study accounts for seasonal variation in daily temperature dynamics by constructing separate equations for each month of the year. By basing this assessment on actually observed sub-daily temperature on site, this approach can adequately capture site-specific dynamics, such as shading by surrounding mountains.

Compared with our earlier analysis, which was largely based on analysis of observed chill levels and only considered (relatively crude) stochastic scenarios for the future, in the present study, we introduced stochastic temperature scenarios for eight past scenario years. Such scenarios facilitate detection of temporal changes in agroclimatic conditions. They also provide opportunities for quantitative risk assessment for growers aiming to cultivate tree species and cultivars with particular chill needs, since they can be used to determine chill levels that are likely to be exceeded with a certain probability (Luedeling et al. 2009b).

Our analysis indicated a strong influence of the metrics used to quantify chill on the emerging trend in chill availability. While the Chilling Hours model diagnosed chill declines by $81 \%, 60 \%$ and $53 \%$ over the historic record for Masayrat ar Ruwajah, Qasha' and Al 'Ayn, respectively, the Dynamic Model only estimated a decline by $75 \%, 35 \%$ and $18 \%$. It is worth noting that for Masayrat ar Ruwajah, the strong relative decline resulted largely from the very low absolute chill levels, especially for the Dynamic Model (i.e. a decline from 4 CP in 1991 to $1 \mathrm{CP}$ in 2018). This observation confirms earlier assessments demonstrating that chill models are far from equivalent (Luedeling and Brown 2011), with the Chilling Hours model being 
highly sensitive to temperature change, especially in warm climates (Luedeling et al. 2009c). Given that the Chilling Hours model has often been found to perform poorly in such climates (Luedeling 2012), we do not recommend its use in climate change adaptation planning. This is especially relevant for warm regions such as the oases of Wadi Muaydin, where using an excessively sensitive model may lead to strong overestimations of climatic risks. The Chilling Hours model includes two hard thresholds, with chill effectiveness suddenly rising from 0 to $100 \%$ at $0{ }^{\circ} \mathrm{C}$ and dropping back to $0 \%$ at $7.2{ }^{\circ} \mathrm{C}$. Such sudden and radical changes, which make this model highly sensitive to warming, do not appear biologically plausible (Campoy et al. 2011; Luedeling 2012; Luedeling et al. 2009c).

Available winter chill is a major determinant of the array of deciduous fruit species that can be grown in a specific location. The low chill levels at Masayrat ar Ruwajah, the lowestelevation oasis, do not allow commercially viable cultivation of such trees. While the survey underlying the analysis of Luedeling et al. (2009a) identified a total of 70 individuals of deciduous fruit trees in this oasis (specifically 30 peach trees, 20 grape vines (Vitis vinifera L.), 13 figs (Ficus carica L.), 5 pomegranates, 1 apricot and 1 plum), these trees did not appear productive and made up $<5 \%$ of all trees. Instead, warm-climate species such as date palm (Phoenix dactylifera L., 956 individuals), banana (Musa spp., 216), citrus (Citrus spp., 168), guava (Psidium guajava L., 18), papaya (Carica papaya L., 14) and mango (Mangifera indica L., 3) dominated the orchards of this oasis. Oases at higher elevations instead, only included very few specimens of tropical tree species (Luedeling et al. 2009a). Pomegranates, roses (Rosa $x$ damascena) and peaches were the most common woody perennials in these oases, with occasional walnut, apricot, almond (Prunus dulcis [Mill.] D.A. Webb) and even apple and pear trees being grown on the terraced fields. This pattern appears to reflect chill availability along the elevation gradient and is typical of Omani mountain oases as shown by comparative studies of Gebauer et al. (2007) and Hammer et al. (2009).

The present assessment cannot produce much evidence for validating chill models, since we do not have information on tree phenology or performance. However, agricultural census data from Oman's Ministry of Agriculture and Fisheries (Al-Kalbani et al. 2016) suggest a dramatic decline in the number of trees of most high-chill species between 2004/2005 and $2012 / 2013$, including peach $(-96 \%)$, apricot $(-89 \%)$, grape $(-86 \%)$, fig $(-92 \%)$, pear ($91 \%)$, apple $(-89 \%)$ and plum $(-100 \%)$. Another account of changes in the species composition in these oases between 2007 and 2018 has recently been presented by Buerkert et al. (under review), who reported that the upper oases of Wadi Muaydin (Al 'Ayn, Al 'Aqr and Ash Sharayjah) have lost $98 \%$ of their apple trees (from 47 to 1 specimens), $81 \%$ of apricots (205 to 40), 24\% of figs (34 to 26), $50 \%$ of grapes (104 to 52), $60 \%$ of peaches (306 to 121), $82 \%$ of plums ( 11 to 2 ) and $41 \%$ of walnuts (45 to 29 ). Similar changes were also noted for the other oases.

Without further inquiry, attributing changes in the abundance of particular tree species to the chill decline may possibly be erroneous, even though the relative persistence of pomegranates $(-8 \%)$ and roses $(-5 \%)$ indicates that low-chill species may have proven to be more viable. An alternative explanation may be that the enhanced focus on rose and pomegranate cultivation results from the superior economic significance of locally produced rosewater and pomegranate fruit, which are cultural icons of the region that are in high demand throughout the country-much more so than the other agricultural commodities of the region which can be readily imported into Oman. We suspect, however, that chill changes contributed to the observed changes in orchard compositions reported by Al-Kalbani et al. (2016). 
For future scenarios, all oases are expected to experience major chill losses, which will likely impact agroclimatic suitability for a number of fruit species. For Al 'Ayn, these scenarios indicate future chill levels that roughly correspond to those currently observed in Qasha'. The array of species that are cultivated in Qasha' was quite similar to that of Al 'Ayn in our earlier survey (Luedeling et al. 2009a), indicating that most species should remain viable throughout most of the twenty-first century. This conclusion is contradicted, however, by the report by Al-Kalbani et al. (2016) that many of these species had largely disappeared by 2012/2013. For all species, but especially for those with high chill needs, it appears likely that the risk of chill shortfalls will increase and that some species may no longer be viable. We are not aware of any information on the specific chilling requirements of cultivars grown in Wadi Muaydin, or of any consideration of such information in selecting cultivars for the oases. The existence of a number of clearly unproductive trees in all locations, especially in the warmest oasis at Masayrat ar Ruwajah, may indicate that oasis farmers are not yet well aware of chill-related production risks.

It seems certain that at some point during the course of the twenty-first century, tree crops that are cultivated in Qasha', and possibly also in Al 'Ayn and other settlements at similar elevation, will reach the limit of their agroclimatic plasticity. Projections indicate that winters will eventually become too warm for fruit-set of some of the species grown. Farmers who still depend on tree crops rather than on new economic opportunities opened by the current socio-economic transformation in Oman's oases may then have to consider adopting new tree cultivars and possibly new species (Luedeling 2020a). An indication that this process is already ongoing in our study area is the increasingly widespread introduction of olive (Olea europaea L.), sponsored by Oman's Ministry of Agriculture (MAF - Ministry of Agriculture and Fisheries, 2014; Buerkert et al. unpublished data). For the traditional species of Al Jabal Al Akhdar, however, selection of adequate germplasm can be challenging. Despite recent progress in dormancy research (Fadón et al. 2020), scientific understanding of dormancy biology, chill accumulation and the climatic requirements of tree cultivars is still relatively rudimentary and offers little practical guidance for adapting orchards near the margins of current distribution ranges (Guo et al. 2019). In the absence of a full understanding of species-specific crop responses to warming and of the regional intensity of climate change, climate analogues may offer some indications of the range of crops that can thrive under future conditions (Luedeling 2012). Climate analogues are learning locations that currently experience climate that is similar to the projected future climate at the location of interest (Ramírez-Villegas et al. 2011). While such locations are often too far away or too dissimilar from the target location to serve as useful models for adaptation (Bos et al. 2015), oasis farmers of Wadi Muaydin may find near-perfect analogues, with slightly warmer temperature conditions and very similar cultural settings, right in their neighbourhood-along the temperature gradient presented by the high-altitude canyon of Wadi Muaydin.

\section{Conclusions}

In the studied oases of Wadi Muaydin, winter chill accumulation has substantially decreased, as shown by simulations of past scenarios, and is projected to continue 
declining until the end of the twenty-first century due to climate change. By 2050, locations at lower elevations such as Masayrat ar Ruwajah are projected to lose virtually all winter chill (regardless of whether it is measured in Chill Portions or in Chilling Hours). In such conditions, only warm-climate species such as date palm, banana and citrus are likely to continue to thrive. At Al 'Ayn, the highest-elevation oasis, future winter chill may decrease to levels observed in the past at Qasha'. Declining winter chill is therefore expected to shift the array of temperate species that are cultivated in these oases, possibly preventing the production of temperate fruits such as stone and pome fruits or forcing farmers to plant varieties with low chill requirements. The climate should remain suitable for low-chill species such as pomegranate and rose. Climate change impacts, that may translate into a modified array of suitable species through declining winter chill, are therefore likely to affect the availability and sale of fresh fruit in Oman's mountain oases. May thus change the array of crops that can be grown, diminish opportunities for the sale of fresh fruit and compromise the sustainability of local agricultural systems. Compared with the previous study in the same watershed, we provide improved procedures for handling weather data and for assessing past and future climate scenarios. These procedures may help develop reliable tools, based on likely ranges of temperatures rather than specific point estimates, to explore the effects of climate change on deciduous fruit tree orchards. Our data also highlight the greater sensitivity of the Chilling Hours model compared with the Dynamic Model, and suggest reconsidering its use in agroclimatic assessments.

Acknowledgments The authors are thankful for the cooperation of the oasis farmers of Al 'Ayn, Qasha' and Masayrat ar Ruwajah where climate data were recorded for 15 years. We would also like to acknowledge the Agricultural Extension Center of the Ministry of Agriculture and Fisheries in Sayh Qatanah, Al Jabal Al Akhdar, Sultanate of Oman, in particular Salim bin Rashed Al Tubi for infrastructural support, the friendship of Dr. Mohamed Al Rawahi, The Research Council, Muscat, and the patient advice during multiple data collection missions of Dr. Eva Schlecht, Universität Kassel and Georg-August-Universität Göttingen Germany. The German Research Foundation (DFG) contributed to travel funding for this study within the Research Training Group GRK1397 and the Research Unit FOR2432 (BU1308/13-1,2).

Authors' contributions AB collected the temperature data, conceived the research hypothesis and wrote the first draft. EL developed the code for past and future assessments of climate-related metrics. EF and BT implemented the code, performed the simulations and wrote parts of the results and the conclusions. All authors contributed in writing the manuscript.

Funding Open Access funding enabled and organized by Projekt DEAL.

\section{Compliance with ethical standards}

Conflict of interest The authors declare that they have no conflict of interest.

Open Access This article is licensed under a Creative Commons Attribution 4.0 International License, which permits use, sharing, adaptation, distribution and reproduction in any medium or format, as long as you give appropriate credit to the original author(s) and the source, provide a link to the Creative Commons licence, and indicate if changes were made. The images or other third party material in this article are included in the article's Creative Commons licence, unless indicated otherwise in a credit line to the material. If material is not included in the article's Creative Commons licence and your intended use is not permitted by statutory regulation or exceeds the permitted use, you will need to obtain permission directly from the copyright holder. To view a copy of this licence, visit http://creativecommons.org/licenses/by/4.0/. 


\section{References}

Al Khanjari S, Hammer K, Buerkert A, Roder MS (2007a) Molecular diversity of Omani wheat revealed by microsatellites: I. Tetraploid landraces. Genet Resour Crop Evol 54:1291-1300

Al Khanjari S, Hammer K, Buerkert A, Roder MS (2007b) Molecular diversity of Omani wheat revealed by microsatellites: II. Hexaploid landraces. Genet Resour Crop Evol 54:1407-1417

Al-Kalbani MS, John C, Martin FP (2015) Recent trends in temperature and precipitation in Al Jabal Al Akhdar, Sultanate of Oman, and the implications for future climate change. J Earth Sci Clim Change 6:295

Al-Kalbani MS, Price MF, O'Higgins T, Ahmed M, Abahussain A (2016) Integrated environmental assessment to explore water resources management in Al Jabal Al Akhdar, Sultanate of Oman. Reg Envir Chang 16: 1345-1361

Al-Rawahi MN, Brinkmann K, Schlecht E, Buerkert A (2014) Effects of changing water availability on land use in irrigated mountain oases of Al Jabal Al Akhdar, northern Oman. Erde 145:197-211

Al-Rawahi MN, Melapie M, Schlecht E, Buerkert A (2017) Carbon and nutrient balances in three mountain oases in Northern Oman. J Agric Mar Sci 22:75-86

AlSarmi S, Washington R (2011) Recent observed climate change over the Arabian peninsula. J Geophys ResAtmos 116:15

AlSarmi SH, Washington R (2014) Changes in climate extremes in the Arabian Peninsula: analysis of daily data. Int J Climatol 34:1329-1345

Benmoussa H, Ben Mimoun M, Ghrab M, Luedeling E (2018) Climate change threatens central Tunisian nut orchards. Int J Biometeorol 62:2245-2255

Bontenbal M (2016) Population, migration and urbanization in Oman. In: Nebel S, von Richthofen A (eds) Urban Oman - trends and perspectives of urbanisation in Muscat Capital Area. HABITAT INTERNATIONAL: Schriften zur Internationalen Stadtentwicklung 21, LIT Verlag Berlin, Germany, pp $29-40$

Bos SPM, Pagella T, Kindt R, Russell AJM, Luedeling E (2015) Climate analogs for agricultural impact projection and adaptation-a reliability test. Front Environ Sci 3:18

Buerkert A, Nagieb M, Siebert S, Khan I, Al-Maskri A (2005) Nutrient cycling and field-based partial nutrient balances in two mountain oases of Oman. Field Crops Res 94:149-164

Campoy JA, Ruiz D, Egea J (2011) Dormancy in temperate fruit trees in a global warming context: a review. Sci Hortic 130:357-372

Cariou A (2017) Liwa: the mutation of an agricultural oasis into a strategic reserve dedicated to a secure water supply for Abu Dhabi. In: Lavie E, Marshall A (eds) Oases and globalization. Ruptures and Continuities. Springer, The Netherlands, pp. 213-225

Chmielewski FM, Blumel K, Palesova I (2012) Climate change and shifts in dormancy release for deciduous fruit crops in Germany. Clim Res 54:209-219

Cordano E, Eccel E (2019) RMAWGEN (R Multi-Site Auto-Regressive Weather GENerator), a package to generate daily time series of precipitation and temperature from monthly mean values. $\mathrm{R}$ package version 1.3 .7

Darbyshire R, Measham P, Goodwin I (2016) A crop and cultivar-specific approach to assess future winter chill risk for fruit and nut trees. Clim Chang 137:541-556

del Barrio R, Fernandez E, Brendel AS, Whitney C, Campoy JA, Luedeling E (2020) Climate change impacts on agriculture's southern frontier - perspectives for farming in North Patagonia. Int J Climatol n/a doi: https://doi.org/10.1002/joc.6649

Dickhoefer U, Buerkert A, Brinkmann K, Schlecht E (2010) The role of pasture management for sustainable livestock production in semi-arid subtropical mountain regions. J Arid Environ 74:962-972

Erez A, Fishman S, Linsley-Noakes GC, Allan P (1990) The dynamic model for rest completion in peach buds. Acta Hort 276:165-174

Fadón E, Fernandez E, Behn H, Luedeling E (2020) A conceptual framework for winter dormancy in deciduous trees. Agronomy 10:241

Fernandez E, Whitney C, Cuneo IF, Luedeling E (2020a) Prospects of decreasing winter chill for deciduous fruit production in Chile throughout the 21st century. Clim Chang 159:423-439

Fernandez E, Whitney C, Luedeling E (2020b) The importance of chill model selection - a multi-site analysis. Eur J Agron 119:126103

Fishman S, Erez A, Couvillon GA (1987a) The temperature-dependence of dormancy breaking in plants computer-simulation of processes studied under controlled temperatures. J Theor Biol 126:309-321

Fishman S, Erez A, Couvillon GA (1987b) The temperature-dependence of dormancy breaking in plants mathematical-analysis of a 2-step model involving a cooperative transition. J Theor Biol 124:473-483

Funsch L (2015) Oman reborn: balancing tradition and modernization. Palgrave, Macmillan, Hampshire, England doi:https://doi.org/10.1057/9781137502018 
Gebauer J, Luedeling E, Hammer K, Nagieb M, Buerkert A (2007) Mountain oases in northern Oman: an environment for evolution and in situ conservation of plant genetic resources. Genet Resour Crop Evol 54: 465-481

Gebauer J, Luedeling E, Hammer K, Buerkert A (2009) Agro-horticultural biodiversity in mountain oases of northern Oman. Acta Horticulturae (ISHS) 817:325-332

Golombek SD, Gebauer J, Buerkert A (2007) Photosynthetic water-use efficiency of irrigated winter and summer crops in a typical mountain oasis of northern Oman. J Plant Nutr Soil Sci 170:98-105

Guo L et al (2019) Distribution margins as natural laboratories to infer species' flowering responses to climate warming and implications for frost risk. Agric For Meteorol 268:299-307

Hammer K, Gebauer J, Al Khanjari S, Buerkert A (2009) Oman at the cross-roads of inter-regional exchange of cultivated plants. Genet Resour Crop Evol 56:547-560

Hourani GF, Carswell J (1995) Arab Seafaring: in the Indian ocean in ancient and early medieval times. Princeton University Press, New York

Hüneburg L et al (2019) Living at the wadi - integrating geomorphology and archaeology at the oasis of Qurayyah (NW Arabia). J Maps 15:215-226

Kwarteng AY, Dorvlo AS, Kumar GTV (2009) Analysis of a 27-year rainfall data (1977-2003) in the Sultanate of Oman. Int J Climatol 29:605-617

Linvill DE (1990) Calculating chilling hours and chill units from daily maximum and minimum temperature observations. HortScience 25:14-16

Luedeling E (2012) Climate change impacts on winter chill for temperate fruit and nut production: a review. Sci Hortic 144:218-229

Luedeling E (2018) Interpolating hourly temperatures for computing agroclimatic metrics. Int J Biometeorol 62 : 1799-1807

Luedeling E (2019) chillR: statistical methods for phenology analysis in temperate fruit trees. R package version 0.70 .21

Luedeling E (2020a) The challenge of warming winters - do we understand tree dormancy enough to prepare deciduous orchards in warm places? Acta Horticulturae (ISHS) 1281:441-447

Luedeling E (2020b) Future chill risk assessment using chillR. Acta Horticulturae (ISHS) 1280:225-232

Luedeling E, Brown PH (2011) A global analysis of the comparability of winter chill models for fruit and nut trees. Int J Biometeorol 55:411-421

Luedeling E, Buerkert A (2008) Effects of land use changes on the hydrological sustainability of mountain oases in northern Oman. Plant Soil 304:1-20

Luedeling E, Nagieb A, Wichern F, Brandt M, Deurer M, Buerkert A (2005) Drainage, salt leaching and physico-chemical properties of irrigated man-made terrace soils in a mountain oasis of northern Oman. Geoderma 125:273-285

Luedeling E, Gebauer J, Buerkert A (2009a) Climate change effects on winter chill for tree crops with chilling requirements on the Arabian Peninsula. Clim Chang 96:219-237

Luedeling E, Zhang MH, Girvetz EH (2009b) Climatic changes lead to declining winter chill for fruit and nut trees in California during 1950-2099. PLoS One 4:9

Luedeling E, Zhang MH, Luedeling V, Girvetz EH (2009c) Sensitivity of winter chill models for fruit and nut trees to climatic changes expected in California's Central Valley. Agric Ecosyst Environ 133:23-31

MAF - Ministry of Agriculture and Fisheries (2014) Annual report 2014: directorate general of agriculture and livestock research. Ministry of Agriculture and Fisheries, Muscat

Mann HB (1945) Nonparametric test against trend. Econometrica 13:245-259

R Core Team (2020) R: a language and environment for statistical computing R Foundation for Statistical Computing. Version 4.0.0 Vienna, Austria

Ramírez-Villegas J et al (2011) Climate analogues: finding tomorrow's agriculture today. Working Paper 12. Copenhagen, Denmark: CCAFS

Siebert S, Nagieb M, Buerkert A (2007) Climate and irrigation water use of a mountain oasis in northern Oman. Agric Water Manag 89:1-14

Stuart A (1956) Rank correlation methods. By M. G. Kendall, 2nd edition vol 9. British Journal of Statistical Psychology, vol 1. John Wiley \& Sons, Ltd (10.1111). doi:https://doi.org/10.1111/j.2044-8317.1956. tb00172.x

Weinberger JH (1950) Chilling requirements of peach varieties. Proc Am Soc Hortic Sci 56:122-128

Wichern F, Luedeling E, Muller T, Joergensen RG, Buerkert A (2004) Field measurements of the $\mathrm{CO}_{2}$ evolution rate under different crops during an irrigation cycle in a mountain oasis of Oman. Appl Soil Ecol 25:85-91 
Wilkinson JC (1977) Water and tribal settlement in south-East Arabia. A study of the Aflāj of Oman. Clarendon Press, Oxford

Wilks DS, Wilby RL (1999) The weather generation game: a review of stochastic weather models. Prog Phys Geogr 23:329-357

Zhang P, Dreisigacker S, Buerkert A, Alkhanjari S, Melchinger AE, Warburton ML (2006) Genetic diversity and relationships of wheat landraces from Oman investigated with SSR markers. Genet Resour Crop Evol 53: $1351-1360$

Publisher's note Springer Nature remains neutral with regard to jurisdictional claims in published maps and institutional affiliations.

\section{Affiliations}

\section{Andreas Buerkert ${ }^{1} \cdot$ Eduardo Fernandez $^{2} \cdot$ Beke Tietjen $^{1} \cdot$ Eike Luedeling $^{2}$}

Eduardo Fernandez

efernand@uni-bonn.de

Beke Tietjen

beke@tietjen.de

Eike Luedeling

luedeling@uni-bonn.de

1 Organic Plant Production and Agroecosystems Research in the Tropics and Subtropics (OPATS), University of Kassel, Steinstrasse 19, D-37213 Witzenhausen, Germany

2 Department of Horticultural Sciences, Institute of Crop Science and Resource Conservation (INRES), University of Bonn, Auf dem Hügel 6, D-53121 Bonn, Germany 